\title{
Analysis of influencing factors of gas injection development in fractured pore carbonate reservoirs
}

\author{
Song Heng ${ }^{1}$, Wu Xuelin ${ }^{1}$, Li Jianxin ${ }^{1}$ and Liu fan ${ }^{2,3}$ \\ ${ }^{1}$ PetroChina, Research Institute of Petroleum Exploration \& Development, 100083 Beijing, China \\ ${ }^{2}$ CNOOC, CNOOC Research Institute Ltd, 100028 Beijing, China \\ ${ }^{3}$ State Key Laboratory of Offshore Oil Exploitation, 100028 Beijing, China
}

\begin{abstract}
Zhanazhol is a weakly volatile reservoir of fractured pore carbonate. The reservoir has poor physical properties and strong heterogeneity. During injection development, the pressure of injection wells is severe and the effect of water injection is not obvious. Making full use of abundant associated gas resources for gas injection development is the best way to stabilize and restore formation pressure and improve oilfield development effectiveness. In order to clarify the impact of different geological characteristics and development parameters on the gas injection development effect of fractured pore carbonate reservoirs, an orthogonal test method was used to analyze the main influencing factors of gas injection development. Studies have shown that the order of the influence of various parameters on gas injection development from high to low is injection-production ratio, well spacing, oil production rate, gas injection timing, matrix permeability, formation dip angle, fracture volume density, net pay thickness, ratio of horizontal permeability to vertical permeability. The research results provide support for formulating gas injection development technology policies and improving oilfield development effect.
\end{abstract}

\section{Preface}

Located in the eastern margin of the Caspian Sea Basin in Kazakhstan, the zhanazhol oilfield is a fractured and porous carbonate reservoir with layered features. Reservoir permeability and porosity are relatively low, with porosity of $9.9-14 \%$ and permeability of 13.8 $84.2 \mathrm{mD}$. The formation fluid is dominated by weakly volatile light crude oil, the viscosity of the formation crude oil is $0.16-0.60 \mathrm{mPa} . \mathrm{s}$, the original dissolved gasoil ratio is $172-351 \mathrm{~m}^{3} / \mathrm{t}$. Oilfields currently use waterflooding development methods, but due to poor reservoir physical properties, waterflooding development effects in low permeability areas are poor. Taking the low-permeability area in the D South oil reservoir in the zhanazhol oil field as an example, the average porosity is $8.3 \%$, the average permeability is $11.3 \mathrm{mD}$, the water injection capacity of the water injection well is poor, the daily water injection of a single well is $10-50 \mathrm{~m}^{3} / \mathrm{d}$, So the formation pressure is kept at a very low level, which leading to a rapid decline in production at the initial stage of oil production wells, it is necessary to switch development methods to improve oilfield development effect.

The oil field has abundant associated gas resources, which provides convenient conditions for the implementation of gas injection development. However, due to factors such as low gas viscosity, high gas oil mobility ratio, and strong reservoir heterogeneity, the breakthrough of gas usually occurs during reservoir development, leading to recovery efficiency fall ${ }^{[1]}$. Therefore, it is necessary to carry out the analysis and Research on the main control factors of gas injection development, to clarify the effect of different geological reservoir characteristics and development parameters on the development effect of gas injection in fractured pore carbonate reservoirs, and to provide technical support for gas injection development in low porosity and low permeability fractured reservoirs.

\section{Selection of evaluation parameters and methods}

Based on the percolation theory, 10 parameters are selected to analyze the main control factors of gas injection development in fractured porous reservoirs, including six geological parameters: matrix permeability, Vertical to horizontal permeability ratio of matrix, Vertical to horizontal permeability ratio of fracture, formation dip, net pay thickness, and fracture density; four development parameters: oil production rate, injection and production ratio, gas injection timing, and well spacing ${ }^{[2]}$.

Among the 10 parameters, except for the formation dip angle which is designed to be 4 levels, all other parameters are designed to be 5 levels. In order to ensure the adaptability of the research results, the values of the five levels of the parameters are all based on the actual values of the D South oil reservoir in zhanazhol oil field, where the matrix permeability ranges from 5.65 to 113

\footnotetext{
* Corresponding author: wu-xuel@petrochina.com.cn
} 
$\mathrm{mD}$, the vertical to horizontal permeability ratio of matrix range is 0.1 to 1 ; the vertical to horizontal permeability ratio of fracture range is 1 to 100 ; the oil production rate range is $0.4 \%$ to $1.6 \%$; injection to production ratio interval is $0.6 \sim 1.4$; formation dip angle interval is $0 \sim 15^{\circ}$, gas injection timing interval is formation pressure keeping level $40 \% \sim 100 \%$; well spacing interval is $200 \sim 600 \mathrm{~m}$; The interval of net pay thickness is $10-50 \mathrm{~m}$; the fracture density interval is 0.05 $0.25 \mathrm{~cm}^{-1}$ (Table 1). In order to reduce the research workload, 81 numerical simulation schemes were generated using orthogonal experimental design methods, and on this basis, the main controlling factors of gas injection development in carbonate reservoirs were analyzed.

Table 1. Specific value of each parameter.

\begin{tabular}{|c|c|c|c|c|c|c|c|c|c|c|}
\hline $\mathrm{No}$ & $\begin{array}{c}\mathrm{Km} \\
(\mathrm{mD})\end{array}$ & $\begin{array}{c}\mathrm{K}_{\mathrm{mv}} / \mathrm{K}_{\mathrm{mh}} \\
(\mathrm{f})\end{array}$ & $\begin{array}{c}\mathrm{K}_{\mathrm{f}} / \mathrm{K}_{\mathrm{m}} \\
(\mathrm{f})\end{array}$ & $\begin{array}{c}\text { Po } \\
(\%)\end{array}$ & $\begin{array}{c}\text { Injection- } \\
\text { production } \\
\text { ratio(f) }\end{array}$ & $\begin{array}{c}\mathrm{D} \\
\left({ }^{\circ}\right)\end{array}$ & $\begin{array}{c}\mathrm{T} \\
(\%)\end{array}$ & $\begin{array}{c}\mathrm{L} \\
(\mathrm{m})\end{array}$ & $\begin{array}{c}\mathrm{H} \\
(\mathrm{m})\end{array}$ & $\begin{array}{c}\mathrm{Fd} \\
\left(\mathrm{cm}^{-}\right.\end{array}$ \\
\hline 1 & 5.65 & 0.1 & 1 & 0.4 & 0.6 & 0 & 100 & 200 & 10 & 0.05 \\
\hline 2 & 11.3 & 0.3 & 10 & 0.7 & 0.8 & 5 & 85 & 300 & 20 & 0.1 \\
\hline 3 & 22.6 & 0.6 & 20 & 1.0 & 1 & 10 & 70 & 400 & 30 & 0.15 \\
\hline 4 & 56.5 & 0.8 & 50 & 1.3 & 1.2 & 15 & 55 & 500 & 40 & 0.2 \\
\hline 5 & 113 & 1 & 100 & 1.6 & 1.4 & & 40 & 600 & 50 & 0.25 \\
\hline
\end{tabular}

\section{Analysis of the influence of the parameters on gas injection recovery}

Using the Eclipse simulation software can predict the recovery factor of the 81 schemes. Using the BSS (BoxBehnken design) data analysis module of SPSS software to analyze and process the data of different schemes, the influence degree of each parameter on gas injection recovery can be obtained. The analysis of the influence degree of each parameter on the gas injection development effect is as follows:

When the permeability of the matrix is in the range of 5.65 to $113 \mathrm{mD}$, it has a great influence on the development effect of gas injection, and the recovery rate varies from $38.5 \%$ to $54 \%$ (Figure 1). When the matrix permeability is between 5.65 and $22.6 \mathrm{mD}$, the gas injection recovery increases with the increase of matrix permeability; when the matrix permeability is between 22.6 and $113 \mathrm{mD}$, the gas injection recovery decreases with the increase of matrix permeability. The main reason is that with the increase of matrix permeability, the gas breakthrough time of production wells is advanced.

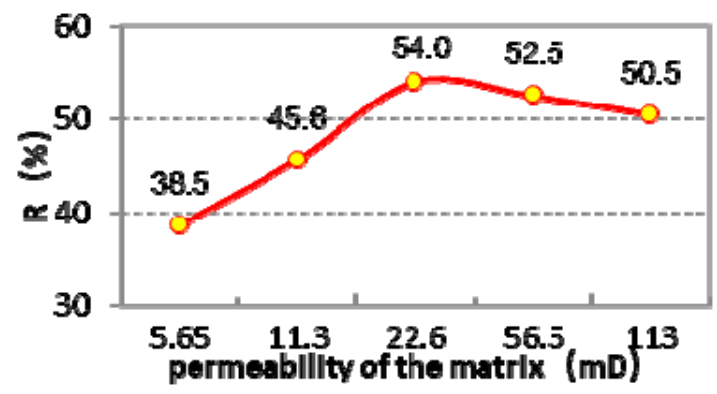

Fig. 1. Effect of different matrix permeability on oil recovery

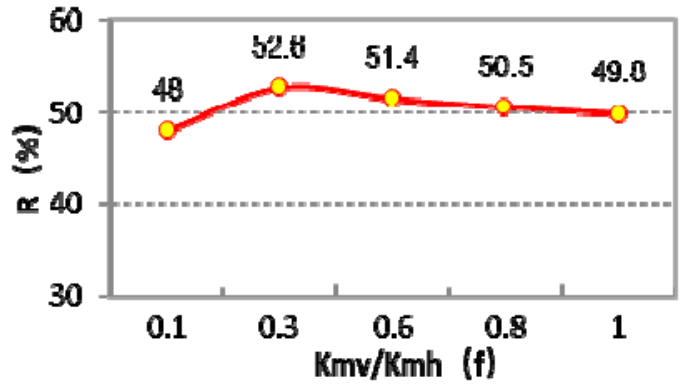

Fig. 2. Effect of different matrix permeability on oil recovery

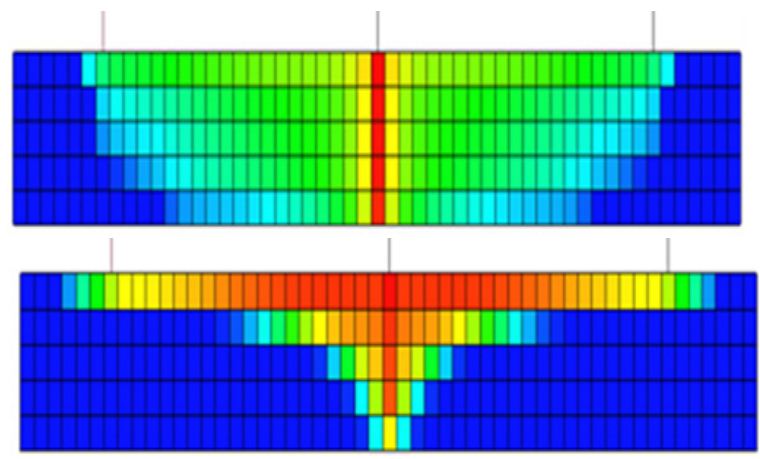

Fig. 3. Comparison of gas displacement effect under different vertical and horizontal permeability ratios of matrix

When the ratio of vertical and horizontal permeability of matrix is between 0.1 and 1 , the effect on gas injection development is less, and the range of recovery is $48.0 \%-52.6 \%$ (Figure 2 ). When the vertical to horizontal permeability ratio of matrix is between 0.1 and 0.3 , the gas injection recovery increases with the increase of vertical to horizontal permeability ratio; When the vertical to horizontal permeability ratio of matrix is between 0.3 and 1.0, the gas injection recovery decreases with the increase of vertical to horizontal permeability ratio. The main reason is that with the increase of vertical and horizontal permeability ratio of matrix, the gravity differentiation is enhanced, and the sweep ability of gas drive in the lower reservoir is weakened. 


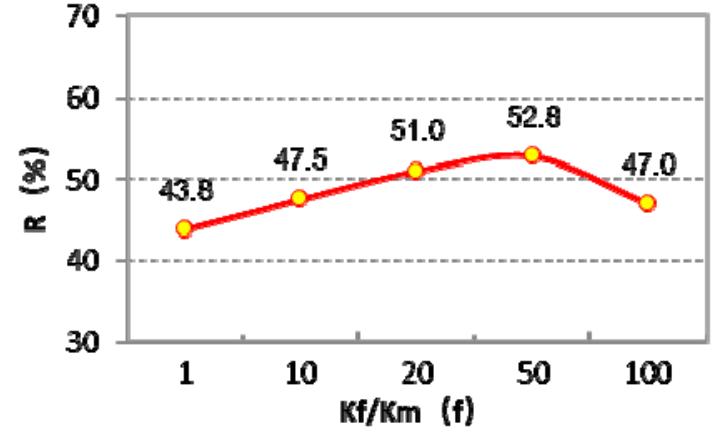

Fig. 4. Effect of different ratio of fracture permeability to matrix permeability on oil recovery

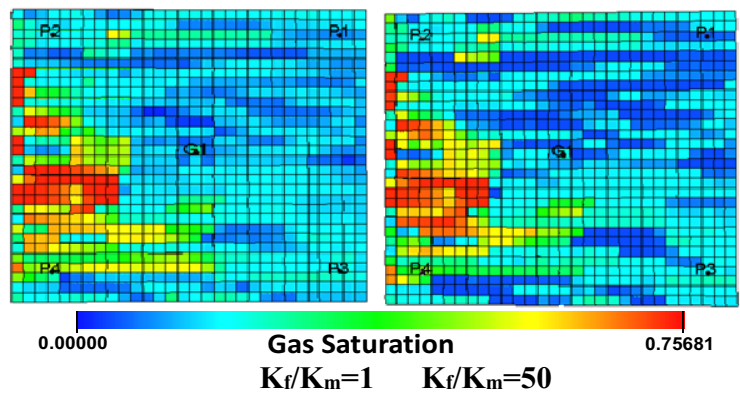

Fig. 5. Comparison of gas displacement effect under different ratio of fracture and matrix permeability

When the ratio of fracture permeability to matrix permeability is between 1 and 100 , it has a greater impact on the development effect of gas injection, and the recovery varies from $43.8 \%$ to $52.8 \%$ (Figure 4 ). When the ratio of fracture permeability to matrix permeability is between 1-50, the gas injection recovery increases as the ratio of fracture permeability to matrix permeability increases; when the ratio of fracture permeability to matrix permeability is between $50-100$, the gas recovery factor decreases as the ratio of fracture permeability to matrix permeability increases. The main reason is that as the fracture permeability increases, the sweep efficiency of the injected gas increases. However, when the fracture permeability is too large, the time of gas channeling in the production well will be advanced.

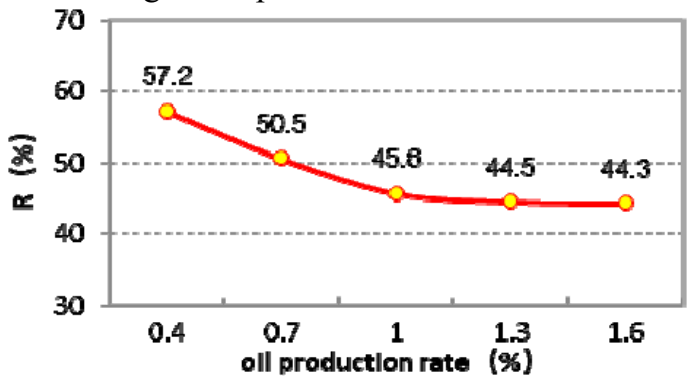

Fig. 6. Effect of different oil production rates on oil recovery

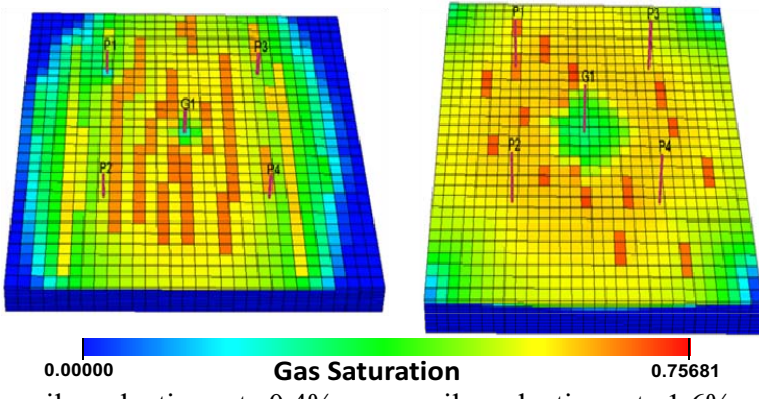

oil production rate $0.4 \% \quad$ oil production rate $1.6 \%$

Fig. 7. Comparison of gas displacement effect by different oil production rates

When the oil production rate is between $0.4 \%$ and $1.6 \%$, it has a greater impact on the development effect of gas injection, and the recovery varies from $44.3 \%$ to $57.2 \%$ (Figure 6 ). On the whole, with the increase of oil production rate, the oil recovery shows a downward trend. The main reason is that with the increase of oil production rate, under the same injection-production ratio, the injection volume of gas injection wells increases greatly, and the time of gas channeling in oil production wells is advanced (Figure 2).

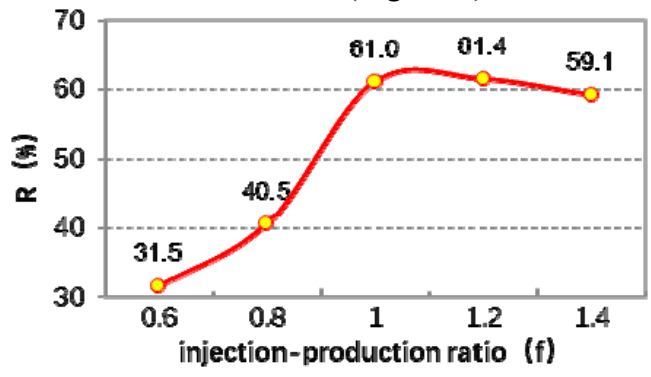

Fig. 8. Effect of different injection-production ratio on oil recovery

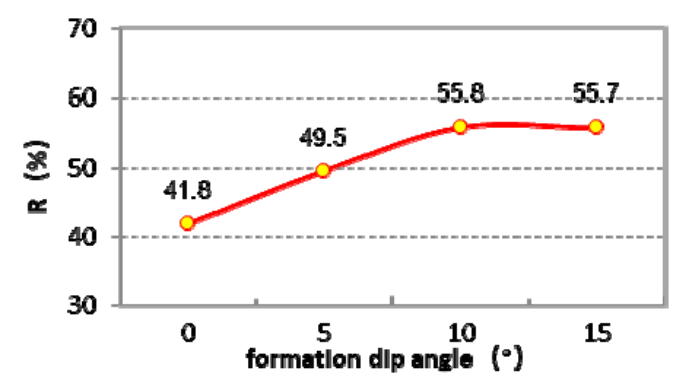

Fig. 9. Effect of different formation dip angles on oil recovery

When the injection-production ratio is between 0.6 and 1.4, it has a great influence on the development effect of gas injection, and the recovery varies from $31.5 \%$ to $61.4 \%$ (Figure 8 ). When the injectionproduction ratio is between 0.6 and 1.0, the gas injection recovery ratio increases with the increase of the injection-production ratio; when the injection-production ratio is between 1.0 and 1.4 , the gas injection recovery decreases slowly with the increase of injection production ratio. The main reason is that the injectionproduction ratio directly affects the formation pressure maintaining level of the reservoir, and the development effect of the reservoir will be improved with the increase 
of the formation pressure maintaining level. However, when the injection-production ratio is too large, the time of gas channeling in some production wells will be ahead of time, resulting in the slow decline of recovery

When the formation dip angle is between $0^{\circ}$ and $15^{\circ}$, it has a greater impact on the gas injection development effect, and the recovery varies from $41.8 \%$ to $55.8 \%$ (Figure9). On the whole, as the formation dip angle increases, the recovery rate of gas injection increases first and then remains stable. The main reason is that when there is formation dip angle, affected by gravity differentiation, the injected gas in the initial stage of gas injection is mainly driven to the high position, resulting in the early shut in of the high-level oil production well. After reaching the high-level boundary, the driving mode of injected gas is converted to the gravity assisted driving mode, driving the remaining oil downward. The larger the dip angle is, the more obvious the effect of gas injection assisted gravity flooding is ${ }^{[3]}$.

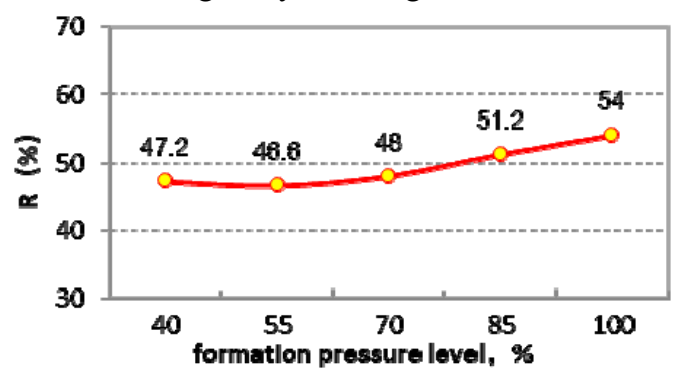

Fig. 10. Effect on oil recovery under different formation pressure maintaining levels

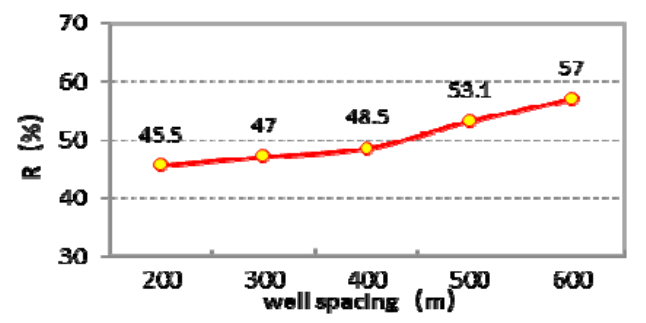

Fig. 11. Effect on oil recovery under different well spacing

The timing of gas injection has little impact on the development effect of gas injection, and the change range of recovery is $46.6 \%-54.0 \%$ (Figure 10 ). With the increase of the formation pressure, the recovery rate increases slowly. The main reason is that the higher the reservoir pressure is, the stronger the miscibility and viscosity reducing ability of injected gas are, the better the development effect is, and the higher the recovery factor is ${ }^{[4]}$.

When the well spacing is between $200 \mathrm{~m}$ and $600 \mathrm{~m}$, it has a greater impact on the development effect, and the recovery varies from $45.5 \%$ to $57.0 \%$ (Figure 11 ). As the well spacing decreases, the recovery factor also shows a downward trend. The main reason is that the smaller the well spacing is, the more likely the production wells are to have gas channeling and the worse the development effect is.

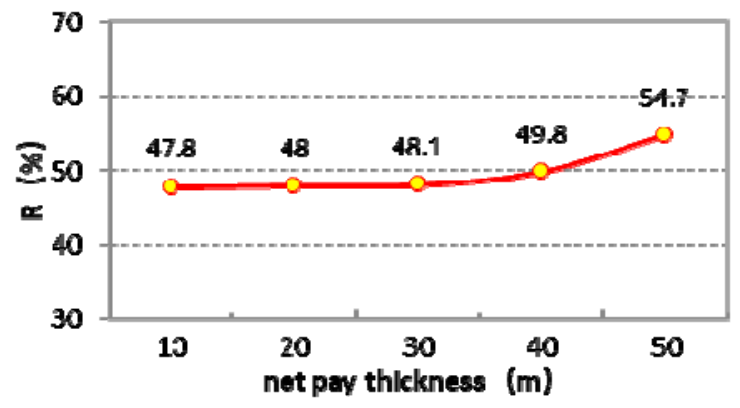

Fig. 12. Effect on oil recovery under different net pay thickness

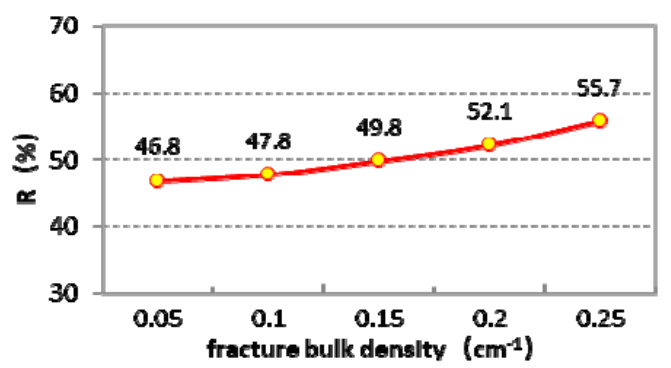

Fig. 13. Effect on oil recovery under different fracture bulk density

When the net pay thickness of the reservoir is between $10 \mathrm{~m}$ and $50 \mathrm{~m}$, the effect on the gas injection development is relatively small, and the recovery varies from $47.8 \%$ to $54.7 \%$ (Figure 12). As the effective thickness increases, the recovery factor tends to increase slowly. The main reason is that when net pay thickness is increased from $10 \mathrm{~m}$ to $50 \mathrm{~m}$, the effect of gas injection assisted gravity displacement is improved and the recovery factor is increased accordingly ${ }^{[5]}$.

When the fracture bulk density is between $0.05 \mathrm{~cm}^{-}$ ${ }^{1}$ and $0.25 \mathrm{~cm}^{-1}$, it has little effect on the gas injection development, and the recovery rate varies from $46.8 \%$ to $55.7 \%$ (Figure 13). With the increase of fracture bulk density, the recovery factor is slowly increasing. The main reason is that as the fracture bulk density increases, the injection gas sweep ability increases, and the recovery rate will also increase. However, at the end of development, the final swept volume of injected gas with different fracture volume density is not much different, which leads to a smaller effect of fracture density on recovery.

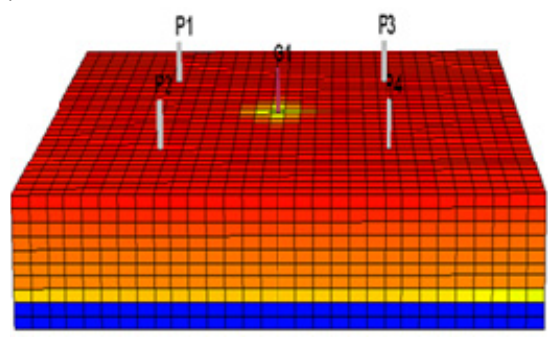

fracture bulk density $0.05 \mathrm{~cm}^{-1}$ 


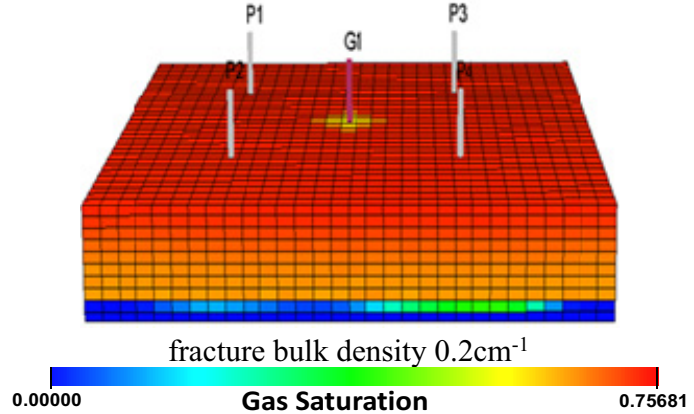

Fig. 14. Gas saturation at the end of development of reservoirs with different fracture bulk density

\section{Analysis of main control factors affecting gas injection development effect}

The order of influence degree of 10 parameters on gas injection recovery can be obtained by BBD method: injection-production ratio $>$ matrix permeability $>$ formation dip angle $>$ oil production rate $>$ well spacing $>$ fracture bulk density $>$ Gas injection timing $>$ net pay thickness $>$ ratio of fracture permeability to matrix permeability $>$ Vertical to horizontal permeability ratio of matrix.

Table 2. The influence of the parameters on recovery of gas injection development.

\begin{tabular}{|c|c|c|c|c|c|}
\hline \multirow[t]{2}{*}{ No } & \multirow[t]{2}{*}{ parameters } & \multicolumn{3}{|c|}{ Recovery interval (\%) } & \multirow[t]{2}{*}{ Ranking } \\
\hline & & minimum & maximum & Difference & \\
\hline 1 & Matrix permeability & 38.5 & 54 & 15.5 & 2 \\
\hline 2 & Vertical to horizontal permeability ratio of matrix & 48 & 52.6 & 4.6 & 10 \\
\hline 3 & Ratio of fracture permeability to matrix permeability & 43.8 & 52.8 & 9 & 6 \\
\hline 4 & oil production rate & 44.3 & 57.2 & 12.9 & 4 \\
\hline 5 & injection-production ratio & 31.5 & 61.4 & 29.9 & 1 \\
\hline 6 & formation dip angle & 41.8 & 55.8 & 14 & 3 \\
\hline 7 & Gas injection timing & 46.6 & 54 & 7.4 & 8 \\
\hline 8 & well spacing & 45.5 & 57 & 11.5 & 5 \\
\hline 9 & net pay thickness & 47.8 & 54.7 & 6.9 & 9 \\
\hline 10 & fracture bulk density & 46.8 & 55.7 & 8.9 & 7 \\
\hline
\end{tabular}

The numerical interval of each evaluation parameter affects the sequence of main control factors of gas injection development in carbonate reservoir. In other words, if the value range of each evaluation parameter is changed, the ranking of main control factors will be affected. In order to reduce the influence of evaluation parameter range on the sequence of main control factors of gas injection, the influence coefficient of oil recovery is introduced. For each evaluation parameter the influence coefficient equals the slope of recovery

Table 3. The coefficient of each evaluation parameter.

\begin{tabular}{|c|c|c|c|}
\hline \multicolumn{2}{|l|}{ Average value of evaluation parameters } & \multirow{2}{*}{$\begin{array}{c}\text { coefficient } \\
0.085\end{array}$} & \multirow{2}{*}{$\begin{array}{c}\text { order } \\
5\end{array}$} \\
\hline $\begin{array}{l}\text { Ratio of matrix permeability to actual matrix permeability in D } \\
\text { South reservoir (f) }\end{array}$ & 3.7 & & \\
\hline Vertical to horizontal permeability ratio of matrix, $f$ & 0.56 & 0.003 & 10 \\
\hline Vertical to horizontal permeability ratio of matrix, $f$ & 36.2 & 0.007 & 9 \\
\hline oil production rate, $\%$ & 1 & 0.106 & 3 \\
\hline injection-production ratio, $\mathrm{f}$ & 1 & 0.380 & 1 \\
\hline formation dip angle, $^{\circ}$ & 7.5 & 0.072 & 6 \\
\hline gas injection timing, $\%$ & $70 \%$ & 0.086 & 4 \\
\hline well spacing, $\mathrm{m}$ & 400 & 0.120 & 2 \\
\hline net pay thickness, $\mathrm{m}$ & 30 & 0.048 & 8 \\
\hline fracture bulk density, cm-1 & 0.15 & 0.071 & 7 \\
\hline
\end{tabular}

\section{Conclusion}

Taking the D south reservoir of zhanazhol Oilfield as the reference, ten evaluation parameters, including reservoir geological characteristics and reservoir development multiply the average value of the evaluation parameters. This coefficient can reflect the contribution rate of different evaluation parameters to the gas injection recovery rate (Table 3 ). The results show that: injectionproduction ratio $>$ well spacing $>$ oil production rate $>$ gas injection timing $>$ matrix permeability $>$ formation dip angle $>$ fracture bulk density $>$ net pay thickness $>$ ratio of fracture permeability to matrix permeability $>$ Vertical to horizontal permeability ratio of matrix.

parameters, are optimized. Except for the formation dip angle of 4 levels, all other parameters are designed as 5 levels. Design of 81 gas injection numerical simulation models based on orthogonal experimental design method.

Using SPSS software BBD data analysis module to analyze and process the data of each scheme and the 
ranking of the influence degree of each evaluation parameter is obtained. Since the value interval of each parameter has a great influence on the ranking of the main control factors, in order to reduce the influence, the influence coefficient of oil recovery is introduced. Based on this, the main control factors of gas injection development in fractured pore carbonate reservoirs are determined as: injection-production ratio $>$ well spacing $>$ oil production rate $>$ gas injection timing $>$ matrix permeability $>$ formation dip angle $>$ fracture bulk density $>$ net pay thickness $>$ ratio of fracture permeability to matrix permeability $>$ Vertical to horizontal permeability ratio of matrix. Among them, the development parameters are ranked in the top four, indicating that although the fracture pore carbonate reservoir storage space is more complicated, the main controlling factor that affects its gas injection development effect is not the geological characteristic factor. It is more important to make a reasonable development technology policy to improve the effect of gas injection development.

$\mathrm{Km}$ : matrix permeability $(\mathrm{mD})$; $\mathrm{Kmv} / \mathrm{Kmh}$ : Vertical to horizontal permeability ratio of matrix(f)

Po: oil production rate $(\%)$ R: oil recovery(f); $\mathrm{D}$ : formation dip angle; $\mathrm{T}$ : gas injection timing $(\%)$

$\mathrm{L}$ : well spacing $(\mathrm{m}) ; \mathrm{H}$ : net pay thickness(m); $\mathrm{Fd}$ : fracture bulk density $\left(\mathrm{cm}^{-1}\right)$

\section{References}

1. H. Qiuxuan, W. Zhiwei, Pet Geol Recovery Effic. 6, 38 (2009)

2. Z Liming, Chem Effic. 44(2018)

3. C. Yuanhao, J. Hanqiao, L Junjian. Sci Tech Eng 16(2016)

4. W. Gaofeng, L. Huahua, L. Jinlong. Sci Tech Eng, 16 (2016)

5. W. Ruisi, Z. Qingqiao, H. Pu. Xijiang Pet Geol, 41(2020). 